\title{
Application of AHP and Fuzzy theory in the Scientific Research Projects Management
}

\author{
Lu Yang ${ }^{1}$, Yanhua Cao ${ }^{1}$, Lijun Zhang ${ }^{2}$ \\ ${ }^{1}$ The Academy of Equipment, Beijing, China; ${ }^{2} 63796$ Unit, Xichang, China.
}

Received 2013

\begin{abstract}
Today, the number of scientific research projects in universities is increasing. The content and system will be more and more complex. The technology in projects will be advanced. And the cost will increase too. The project management involves various factors. More and more uncertain factors will increase the project risk of demonstrating and studying. At present, we still lack the valid means in risk identification, evaluation, control and management in universities. Therefore, the risk management study of scientific research projects has great importance and pressure. In this paper, AHP (Analytic Hierarchy Process) and fuzzy theory are applied into the scientific research projects management. We analyzed the risk factors and determined the indexes. Risk grades and the evaluation model are built. A simulation example is given. The results of our study give references to the risk control and decision of scientific research management, which can be used directly in reality. It also has reference value to other kinds of risk management.
\end{abstract}

Keywords: Risk Management; Risk Evaluation; the Analytical Hierarchy Process (AHP); Fuzzy Theory

\section{Introduction}

With the rapid development of technology and the promotion of management, the demand of quality of scientific research projects is enhancing. Current managing procedures of projects in universities are mostly simple and rough. The accomplishing quality of scientific research projects would be promoted greatly if some infections were detected early and the managing procedure was improved in the management process.

AHP (Analytic Hierarchy Process)[1] is a kind of analyzing method which transfers the experience of decision-makers to quantity. With AHP method, the weight coefficients of indexes are computed based on the sequence of index system. Two indexes are chose each and compared to determine which is better. The weight coefficients are then gotten by synthesis analysis.

Fuzzy sets theory[2] is a kind of quantitative tech- niques for dealing with the vagueness. Fundamental to fuzzy set theory is the notion of using a linguistic variable as a means of estimating the possibility of an event being a member of a given fuzzy set. Linguistic variables differ from a numerical variable in the sense that their values are not numbers, but, rather words or phrases of a natural language. Fuzzy sets then represent restrictions on the values of a given linguistic variable.

In the paper, we apply both AHP and Fuzzy theory into the management of scientific research projects. With AHP method, the indexes of scientific research project management are analyzed. The weight of each index is quantified. With Fuzzy theory, the linguistic variables which indicate the risk degree or the probability can be quantified. Combined with both methods, the risk and probability of management can be calculated, which can provide accurate reference to the scientific research projects management. Results of our study clarify the effect factors of scientific research projects, give advices to keep away risk and are helpful to bring forward the scientific research competition ability of universities.

\section{Indexes Analysis}

Three basic objects of scientific research project management include schedule object, cost object and quality object [3-5]. The final aim of project implement is to make the best of resources and get anticipant quality in anticipant time and cost. But there is conflict between the three objects. The shortening of time asks the increasing of cost, and the lack of time and cost will effect the realization of quality object. Thus the balance of three objects is important. Considering above factors, we choose schedule object, cost object and quality object as the first level indexes of scientific research project management. The ladder frame indexes model of scientific research project management is shown in Figure 1.

Schedule, cost and quality all can be affected by four factors: environment, economy, technology and personnel. 
Thus, they are selected as the indexes in the second level.

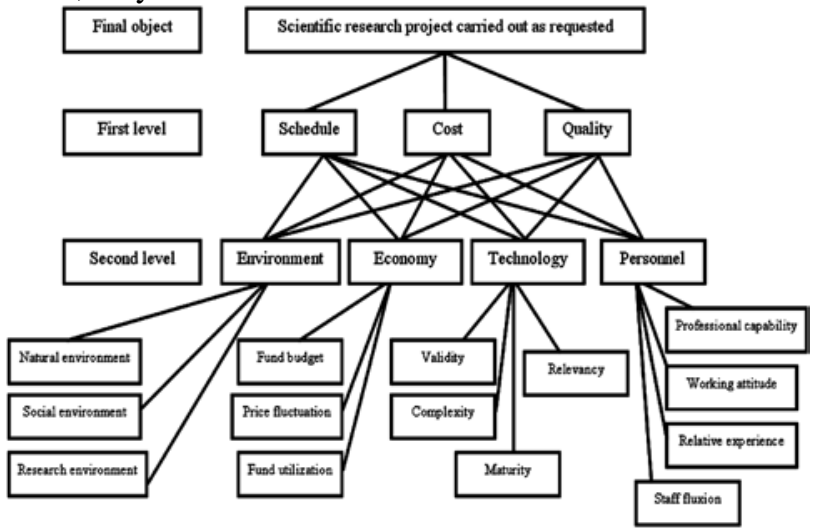

Figure 1. The ladder frame indexes model of scientific research project management.

Environment factors include natural environment, social environment and research environment. The changing of environment can bring uncontrolled risk to the scientific research project, such as earthquake, war, law amending and so on.

Economy factors include fund budget, price fluctuation and fund utilization. The utilization of budget fund has been considered as an important index in scientific research projects examining. If funds carried out were too low, it would be seen as making a false report of fund or lacking related research, which would have bad influence on future project approval. Otherwise, if funds were overspent, it would be seen as not worthy or irrational implement.

Technology factors include validity, complexity, maturity and relevancy. Scientific research project always has difficulty and risk. The quality of project is usually connected with the technology measures used. The risk of project, especially the technology measures, shall be paid enough importance on at the beginning.

Personnel factors include professional capability, working attitude, relative experience and staff fluxion. It's very important to exert the individual initiative in research. Better state of personnel is helpful for the accomplishment of scientific research project at shorter time and in lower cost.

\section{Weight Quantification with AHP}

AHP method is applied to quantify the indexes' weights of scientific research project management. We use 1-9 markers for experts' scoring to build the relative weight matrix between each two indexes. The meanings of 1-9 markers are shown in Table 1. The random index C.R. is shown in Table 2 which will be used in this paper [1].

Comparing one index with another, the judging matrix $A\left(a_{i j}\right)$ can be obtained. Each element $a_{i j}$ in the matrix indicates the relative importance of index $A_{i}$ compared with index $A_{j}$ according to 1-9 markers in Table 2.

Table 1. The meanings of 1-9 markers.

\begin{tabular}{|c|c|}
\hline Marker & Meanings \\
\hline 1 & Compared both factors, they have the same weight. \\
\hline 3 & $\begin{array}{l}\text { Compared both factors, one is slightly more important } \\
\text { than another. }\end{array}$ \\
\hline 5 & $\begin{array}{l}\text { Compared both factors, one is clearly more important } \\
\text { than another. }\end{array}$ \\
\hline 7 & $\begin{array}{l}\text { Compared both factors, one is intensively more impor- } \\
\text { tant than another. }\end{array}$ \\
\hline 9 & $\begin{array}{l}\text { Compared both factors, one is absolutely more impor- } \\
\text { tant than another. }\end{array}$ \\
\hline $2,4,6,8$ & $\begin{array}{l}\text { The middle value between two above-mentioned } \\
\text { neighboring values. }\end{array}$ \\
\hline reciprocal & $\begin{array}{l}\text { If } b_{i j} \text { is the judging result when } i \text { is compared with } j \text {, } \\
b_{j i}=1 / b_{i j} \text { is the judging result when } j \text { is compared with } i\end{array}$ \\
\hline
\end{tabular}

Talbe 2. The random index C.R.

\begin{tabular}{cccccccccccc}
\hline$n$ & 1 & 2 & 3 & 4 & 5 & 6 & 7 & 8 & 9 & 10 & 11 \\
\hline C.R. & 0 & 0 & 0.58 & 0.9 & 1.12 & 1.24 & 1.32 & 1.41 & 1.45 & 1.49 & 1.51 \\
\hline
\end{tabular}

In the first level, we take schedule as $A_{1}$, cost as $A_{2}$ and quality as $A_{3}$. Generally speaking, quality is slightly more important than cost and schedule. Cost is slightly more important than schedule. According to our understanding, we get the judging matrix $A$ as follows.

$$
A=\left[\begin{array}{ccc}
1 & 1 / 3 & 1 / 4 \\
3 & 1 & 1 / 3 \\
4 & 3 & 1
\end{array}\right]
$$

In the second level of Table 1, we have four indexes which is environment $\left(B_{1}\right)$, economy $\left(B_{2}\right)$, technology $\left(B_{3}\right)$ and personnel $\left(B_{4}\right)$. Similarly, compared these indexes with each other separately for the three factors in the first level, we get the judging matrixes $A_{1}, A_{2}$ and $A_{3}$ as follows.

$$
\begin{aligned}
A_{1} & =\left[\begin{array}{cccc}
1 & 3 & 5 & 4 \\
1 / 3 & 1 & 5 & 3 \\
1 / 5 & 1 / 5 & 1 & 1 / 2 \\
1 / 4 & 1 / 3 & 2 & 1
\end{array}\right] \\
A_{2} & =\left[\begin{array}{cccc}
1 & 1 / 5 & 1 / 3 & 1 / 2 \\
5 & 1 & 3 & 4 \\
3 & 1 / 3 & 1 & 2 \\
2 & 1 / 4 & 1 / 2 & 1
\end{array}\right] \\
A_{3} & =\left[\begin{array}{cccc}
1 & 1 / 3 & 1 / 5 & 1 / 5 \\
3 & 1 & 1 / 2 & 1 / 3 \\
5 & 2 & 1 & 2 \\
5 & 3 & 1 / 2 & 1
\end{array}\right]
\end{aligned}
$$

The second level objects of environment $\left(B_{1}\right)$, economy $\left(B_{2}\right)$, technology $\left(B_{3}\right)$ and personnel $\left(B_{4}\right)$ are still affected by the factors such as natural environment $\left(C_{1}\right)$, social 
environment $\left(C_{2}\right)$, research environment $\left(C_{3}\right)$, fund budget $\left(D_{1}\right)$, price fluctuation $\left(D_{2}\right)$, fund utilization $\left(D_{3}\right)$, validity $\left(E_{1}\right)$, complexity $\left(E_{2}\right)$, maturity $\left(E_{3}\right)$, relevancy $\left(E_{4}\right)$, professional capability $\left(F_{1}\right)$, working attitude $\left(F_{2}\right)$, relative experience $\left(F_{3}\right)$ and staff fluxion $\left(F_{4}\right)$. Compared these factor with each other further, we get the judging matrixes $B_{1}, B_{2}, B_{3}$ and $B_{4}$.

$$
\begin{array}{rlrl}
B_{1} & =\left[\begin{array}{ccc}
1 & 1 / 2 & 2 \\
2 & 1 & 3 \\
2 & 1 / 3 & 1
\end{array}\right] & B_{2}=\left[\begin{array}{ccc}
1 & 3 & 1 / 3 \\
1 / 3 & 1 & 1 / 5 \\
3 & 5 & 1
\end{array}\right] \\
B_{3}=\left[\begin{array}{cccc}
1 & 4 & 5 & 2 \\
1 / 4 & 1 & 2 & 1 / 2 \\
1 / 5 & 1 / 2 & 1 & 1 / 3 \\
1 / 2 & 2 & 3 & 1
\end{array}\right] & B_{4}=\left[\begin{array}{cccc}
1 & 1 / 2 & 3 & 2 \\
2 & 1 & 7 & 3 \\
1 / 3 & 1 / 7 & 1 & 1 / 2 \\
1 / 2 & 1 / 3 & 2 & 1
\end{array}\right]
\end{array}
$$

The eigenvectors can be computed according to the judging matrixes we got above. First we transfer the judging matrix $A$ to a new matrix $X$. Then eigenvector $W$ can be got from matrix $X$. The elements $x_{i}$ in $X$ and $w_{i}$ in $W$ have special relation with the elements $a_{i j}$ in A as follows.

$$
\begin{aligned}
& x_{i}=\frac{1}{n} \sum_{j=1}^{n} a_{i j}, n \text { is the size of matrix } A . \\
& w_{i}=x_{i} / \sum_{i=1}^{n} x_{i}
\end{aligned}
$$

Thus the eigenvectors $W, W_{1}, W_{2}, W_{3}, W_{B 1}, W_{B 2}, W_{B 3}$ and $W_{B 4}$ of judging matrixes $A, A_{1}, A_{2}, A_{3}, B_{1}, B_{2}, B_{3}$ and $B_{4}$ is obtained.

$$
\begin{aligned}
& W=\left[\begin{array}{l}
0.1138 \\
0.3114 \\
0.5749
\end{array}\right], \quad W_{1}=\left[\begin{array}{l}
0.4673 \\
0.3355 \\
0.0683 \\
0.1288
\end{array}\right], \\
& W_{2}=\left[\begin{array}{l}
0.0810 \\
0.5176 \\
0.2522 \\
0.1493
\end{array}\right], \quad W_{3}=\left[\begin{array}{l}
0.0665 \\
0.1854 \\
0.3836 \\
0.3645
\end{array}\right], \\
& W_{B 1}=\left[\begin{array}{l}
0.3088 \\
0.5294 \\
0.1618
\end{array}\right], \quad W_{B 2}=\left[\begin{array}{l}
0.2915 \\
0.1031 \\
0.6054
\end{array}\right] \text {, } \\
& W_{B 3}=\left[\begin{array}{l}
0.4942 \\
0.1544 \\
0.0837 \\
0.2677
\end{array}\right], \quad W_{B 4}=\left[\begin{array}{l}
0.2568 \\
0.5136 \\
0.0781 \\
0.1515
\end{array}\right]
\end{aligned}
$$

During the building process of judging matrixes, the judgment may conflict with each other considering people's subjective understanding. In order to assure the validity of analysis, we check up the consistency as follows.

$$
\begin{gathered}
A \cdot W=\left[\begin{array}{l}
0.3613 \\
0.8443 \\
1.9641
\end{array}\right], \\
\lambda_{\max }=\frac{1}{3}\left(\frac{0.3613}{0.1138}+\frac{0.8443}{0.3114}+\frac{1.9641}{0.5749}\right)=3.1012 \\
\text { C.I. }=0.0506
\end{gathered}
$$

According to Table 3, the random index C.R. is set as 0.58 . The consistency index $C R$ is computed as follows.

$$
C R=\frac{C . I .}{C . R .}=\frac{0.0506}{0.58}=0.0872<0.1
$$

Since $C R<0.1$, It indicates that the consistency of judging matrix $A$ is acceptable and the weight eigenvector $W$ are rational. Similarly, we compute the consistency indexes of other judging matrixes. The consistency indexes $C R$ are 0.0695, 0.0244, 0.0596, 0.0477, 0.0107 and 0.0052 corresponding to $A_{1}, A_{2}, A_{3}, B_{1}, B_{2}, B_{3}$ and $B_{4}$. Thus, the eigenvectors $W_{1}, W_{2}, W_{3}, W_{B 1}, W_{B 2}, W_{B 3}$ and $W_{B 4}$ are all acceptable and can be taken as the weight of each risk factor.

\section{Risk Analysis with Fuzzy Theory}

Risk evaluation is an important content in the risk analysis of scientific research project management. Besides the risk indexes, we need to confirm the risk probability degree and harm degree [6-7]. We usually use linguistic variables to state the probability and harm of various risks, such as "very likely to happen", "contingently to happen”, "infrequently to happen", "very harmful”, "slightly harmful", "harmless" and so on. Thus, we classify both probability and harm degree into five grades as A, B, C, D and E shown in Table 3.

According to the five grades, the risk factors of environment, economy, technology and personnel and their junior risk factors can all be described by similar mode.

Experts' scoring method can be used to obtain the linguistic variables as inputs. Each expert evaluates whether risk factor $A_{i}(i=1,2, \ldots, m)$ belongs to risk grade $D_{j}$ $(j=1,2, \ldots, n)$. Then, the evaluation matrix $R\left(r_{i j}\right)$ can be obtained. The matrix element $r_{i j}$ is computed as follows.

$r_{i j}=\frac{\text { The number of experts who consider risk factor } i \text { belongs to grade } j}{\text { The }}$ The total number of experts

Table 3. The risk grades ( include probability and harm ) description.

\begin{tabular}{ccc}
\hline grade & $\begin{array}{c}\text { Risk probability } \\
\text { (quantitative range) }\end{array}$ & $\begin{array}{c}\text { Risk harm } \\
\text { (quantitative range) }\end{array}$ \\
\hline A & Frequently (100\% 80\%) & Very harmful (100\% 80\%) \\
B & Very likely (80\% 60\%) & Rather harmful (80\% 60\%) \\
\hline
\end{tabular}




\begin{tabular}{ccc}
\hline C & Likely (60\% 40\%) & Generally harmful (60\% 40\%) \\
D & Contingently (40\% 20\%) & Slightly harmful (40\% 20\%) \\
E & Infrequently $(20 \% \sim 0)$ & Rarely harmful (20\% 0) \\
\hline & $R=\left[\begin{array}{cccc}r_{11} & r_{12} & \cdots & r_{1 n} \\
r_{21} & r_{22} & \cdots & r_{2 n} \\
\cdots & \cdots & \cdots & \cdots \\
r_{m 1} & r_{m 2} & \cdots & r_{m n}\end{array}\right]$
\end{tabular}

Combining evaluation matrix $R$ with weight matrix $W$, we can get the fuzzy evaluation set $B$.

$$
\begin{gathered}
B=W \cdot R=\left[w_{1}, w_{2}, \ldots, w_{m}\right] \cdot\left[\begin{array}{cccc}
r_{11} & r_{12} & \cdots & r_{1 n} \\
r_{21} & r_{22} & \cdots & r_{2 n} \\
\cdots & \cdots & \cdots & \cdots \\
r_{m 1} & r_{m 2} & \cdots & r_{m n}
\end{array}\right]=\left[b_{1}, b_{2}, \ldots, b_{n}\right] \\
\bar{B}=\left[\bar{b}_{1}, \bar{b}_{2}, \ldots, \bar{b}_{n}\right], \quad \bar{b}_{i}=\frac{b_{i}}{\sum_{i=1}^{n} b_{i}}
\end{gathered}
$$

In the formula above, $\bar{B}$ is the fuzzy synthesis judging matrix and $\bar{b}_{i}(i=1 \ldots n)$ is the fuzzy synthesis judging index.

Here is a simulation example. Supposing there are five experts scoring to an scientific research project. Their evaluation results of indexes $A_{i}(i=1,2, \ldots, 14)$ are shown in Table 4.

The risk probability evaluation matrix $R_{D}$ and the harm evaluation matrix $R_{H}$ is shown as follows:

$$
\begin{aligned}
R_{D} & =\left[\begin{array}{cccccccccccccc}
0 & 0 & 0.2 & 0 & 0 & 0 & 0 & 0 & 0 & 0 & 0.2 & 0 & 0 & 0 \\
0 & 0 & 0.4 & 0.2 & 0 & 0.4 & 0 & 0.2 & 0.4 & 0 & 0.4 & 0.6 & 0.4 & 0 \\
0 & 0 & 0.4 & 0.6 & 0 & 0.4 & 0 & 0.6 & 0.6 & 0.4 & 0.4 & 0.4 & 0.6 & 0 \\
0 & 0.6 & 0 & 0.2 & 0.8 & 0.2 & 0.4 & 0.2 & 0 & 0.4 & 0 & 0 & 0 & 0.2 \\
1 & 0.4 & 0 & 0 & 0.2 & 0 & 0.6 & 0 & 0 & 0.2 & 0 & 0 & 0 & 0.8
\end{array}\right] \\
R_{H} & =\left[\begin{array}{cccccccccccccc}
0.2 & 0 & 0 & 0 & 0 & 0.2 & 0 & 0 & 0 & 0 & 0.2 & 0.4 & 0 & 0 \\
0.6 & 0.2 & 0 & 0.4 & 0 & 0.6 & 0.4 & 0.4 & 0.4 & 0 & 0.4 & 0.4 & 0 & 0 \\
0.2 & 0.4 & 0.4 & 0.6 & 0.2 & 0.2 & 0.6 & 0.6 & 0.4 & 0.6 & 0.4 & 0.2 & 0.2 & 0.4 \\
0 & 0.4 & 0.6 & 0 & 0.6 & 0 & 0 & 0 & 0.2 & 0.4 & 0 & 0 & 0.8 & 0.6 \\
0 & 0 & 0 & 0 & 0.2 & 0 & 0 & 0 & 0 & 0 & 0 & 0 & 0 & 0
\end{array}\right]
\end{aligned}
$$

\begin{tabular}{|c|c|c|c|c|c|c|c|c|c|c|}
\hline & \multicolumn{5}{|c|}{ Risk probability (number of experts) } & \multicolumn{5}{|c|}{ Risk harm (number of experts) } \\
\hline & A & B & $\mathrm{C}$ & $\mathrm{D}$ & E & A & B & C & $\mathrm{D}$ & $\mathrm{E}$ \\
\hline Natural environment & 0 & 0 & 0 & 0 & 5 & 1 & 3 & 1 & 0 & 0 \\
\hline Social environment & 0 & 0 & 0 & 3 & 2 & 0 & 1 & 2 & 2 & 0 \\
\hline Research environment & 1 & 2 & 2 & 0 & 0 & 0 & 0 & 2 & 3 & 0 \\
\hline Fund budget & 0 & 1 & 3 & 1 & 0 & 0 & 2 & 3 & 0 & 0 \\
\hline Price fluctuation & 0 & 0 & 0 & 4 & 1 & 0 & 0 & 1 & 3 & 1 \\
\hline Fund utilization & 0 & 2 & 2 & 1 & 0 & 1 & 3 & 1 & 0 & 0 \\
\hline Validity & 0 & 0 & 0 & 2 & 3 & 0 & 2 & 3 & 0 & 0 \\
\hline Complexity & 0 & 1 & 3 & 1 & 0 & 0 & 2 & 3 & 0 & 0 \\
\hline Maturity & 0 & 2 & 3 & 0 & 0 & 0 & 2 & 2 & 1 & 0 \\
\hline Relevancy & 0 & 0 & 2 & 2 & 1 & 0 & 0 & 3 & 2 & 0 \\
\hline Professional capability & 1 & 2 & 2 & 0 & 0 & 1 & 2 & 2 & 0 & 0 \\
\hline Working attitude & 0 & 3 & 2 & 0 & 0 & 2 & 2 & 1 & 0 & 0 \\
\hline Relative experience & 0 & 2 & 3 & 0 & 0 & 0 & 0 & 1 & 4 & 0 \\
\hline Staff fluxion & 0 & 0 & 0 & 1 & 4 & 0 & 0 & 2 & 3 & 0 \\
\hline
\end{tabular}

Table 4. The evaluation results of experts.

According to the formula above, we obtain the total probability fuzzy synthesis judging matrix $T B_{D}$ and the harm fuzzy synthesis judging matrix $T B_{H}$ of the project. 


$$
T B_{D}=\left[\begin{array}{l}
0.0177 \\
0.2389 \\
0.3080 \\
0.2284 \\
0.2072
\end{array}\right], \quad T B_{H}=\left[\begin{array}{l}
0.1138 \\
0.3541 \\
0.3915 \\
0.1345 \\
0.0063
\end{array}\right],
$$

Choosing the maximum value in each matrix as the final result, it is seen that the total risk probability of the project is $30.8 \%$ and the total harm degree is $39.15 \%$.

\section{REFERENCES}

[1] G. Eason, B. Noble, and I. N. Sneddon, "On certain integrals of Lipschitz-Hankel type involving products of Bessel functions,” Phil. Trans. Roy. Soc. London, vol. A247, pp. 529-551, April 1955. (references)

[2] Jian-ming Shen, "Project Risk Management". Beijing:
Press of mechanical industry. (2003) 110-121. (in Chinese)

[3] Zadeh L A, “Fuzzy Sets. Information and Control”. No. 8 (1965) 338-353.

[4] Bennet P. Lientz, Kathryn. Rea, “Project Management”. For the 21st Century.Third Edition. California: Academic Press. (2002).

[5] Blanchard B S, "Logistics Engineering and Management”.5th ed. New York: Prentice Hall. (1998).

[6] Blanchard B S, "System engineering management”. John Wiley \& Sons. New York. (1997).

[7] Neil J. Tuholski, Henrik Gluver. Etc, "Risk Assessment Procedures for Innovative of Navigation”. U.S. Army corps of Engineers. Washington, DC. (2000)12.

[8] The PMI Standards Committee, "A Guide to the Project Management Body of Knowledge”. Philadelphia: project Management Institute. (1994). 